\title{
Did Economic Crisis Affect Values? The Case of Young Generation in the Czech Republic
}

\author{
Inna Čábelková \\ Charles University in Prague \\ Email: inna.cabelkova@fhs.cuni.cz
}

Doi:10.5901/mjss.2014.v5n23p1599

\begin{abstract}
The theory of modernization and cultural change suggests that socio-economic conditions are correlated with the values prevalent in the population. In the process of socio-economic development human values change from survival values to selfexpression values that result in greater civil and political liberties and broaden people's priority and entitlement to act according to their choices. In this paper we examine the differences in young generation values under three economic conditions - before the last economic crisis, during the crisis and after the main dangers of the crisis were overcome (in 2006, 2010, 2012). The overall size of the sample was 1190 respondents. We find significant shift to survival values in 2010 comparing to 2006 and shift to self-expression values and values supporting civil and political liberties in 2012 comparing to 2006 and 2010. The effect of economic crisis was so pronounced, that self-expression values in 2012 overcome the values in 2006 even though economic expectations of many people did not improve dramatically.
\end{abstract}

Keywords: values; economic crisis; change; young generation

\section{Introduction}

The economic crisis of 2008-2009 introduced numerous changes in the society. Under increased threat of job loss due to the instability of the banking sector and general economic uncertainty, the public is changed its political and value orientations, which is reflected at all levels of the social hierarchy and age groups.

The effects of economic conditions on value system were well described in the theory of modernization and cultural change (Inglehart, Welzel, 2007). Here, in the process of socio-economic development human values change from survival values to self-expression values that result in greater civil and political liberties and broaden people's priority and entitlement to act according to their choices (Inglehart, Welzel, 2007, p. 3). The question arises, what will happen with these priorities if the economic situation temporarily gets worse and then partially improves. This question we study in this paper on the example of value system of three groups of first-year students of the Faculty of Humanities, Charles University in Prague. These students have not yet received much economic knowledge did not have rich experience of productive activities. Therefore, they were neither influenced by economic or social paradigms nor by actual economic processes. For this reason they reflect well the general mood of the society. In this paper we analyze the changes in values of these group of students before the onset of economic crises (in 2006), during the economic crisis (in 2010) and after the main dangers of the economic crisis were overcome (in 2012).

The paper is structures as follows. After the brief introduction we provide literature review on the existing knowledge of the influence of economic crises o value systems. Then we discuss our data and methodology and present the results of our analysis. We found, that values of the respondents showed significant shift from self-expression to survival values in 2010 comparing to 2006 and shift back to self-expression values and values supporting civil and political liberties in 2012 comparing to 2006 and 2010. The effect of economic crisis was so pronounced, that selfexpression values in 2012 overcome the values in 2006 even though economic expectations of many people did not improve dramatically.

\section{Brief Literature Review}

The effect of economic condition on population values is described in the theory of modernization of Inglehart and Welzel (2007) as follows (see also Welzel, 2002, Inglehart, 2004, Inglehart ,2008, Welzel et al., 2003). Firstly, improved economic welfare presents the population with additional choices they are able to take and increases their autonomy. As this aspect becomes more pronounced, it brings cultural changes represented by changes in value system finally making democracy the logical outcome. Though a large part of cultural values is transmitted from one generation to the next and 
is difficult to change (see Hofsdede et al. 2010), some values are based upon the firsthand experience and are subject to change with respect to change in outer factors. These values will be the subject of this paper in the context of the last economic crisis.

The impact of 2008's economic crisis on the value systems in the suffered countries was discussed is academic literature from several perspectives. John Bruton (2012) investigated the effect of the economic crisis in 2008 on the system of values of the right and the central wing of the economic spectrum in the EU. The author theoretically discusses the points on whether value systems in a free market are best expressed on collective actions of individual decisions, the characteristics of Christian democratic value system, the definitions and functions of economic growth and some factor including the value systems that promote economic development. The author concludes, that while economic growth is important, it should be viewed as a mere condition for organizing society in a meaningful way as for the value systems.

Inklaar, Robert and Yang Jing, (2012) investigated the effects of the economic crisis on investment depending on how society can live with the uncertainty of the future, which it characterized by the value of uncertainty avoidance. The authors have shown that in countries with a greater tolerance for uncertainty in the future, the economic impact on investment was smaller, while in smaller uncertainty tolerant countries influence was greater. Thus the value systems may intensify or diminish the effects of economic crisis.

Jackson, Kevin T. (2010) examines the economic crisis in terms of cultural moral value orientations. He discusses the roots and the nature of financial crisis and the possible regulatory responses needed. Then the author adopts value perspective to examine the crisis from cultural point of view. The paper presents several mental models of different actors of economic processes such as economists, businessmen and legal authorities. The author ends with moral-cultural perspective of human values and possible dysfunctions indicated by crisis which are not treated by usual regulations.

Rae, D. (2010) investigated the impact of the economic crisis on the value orientations production manager who should be formed in the course of training at the university. The author suggests, that financial and economic crisis of 2008 influenced the education in the sphere of enterprises and entrepreneurship. He explores this influence and suggests how education can and should response to these new challenges. The author concludes that due to the ethical and environmental concerns there should be more attention paid to responsible entrepreneurship informed by social entrepreneurships

Dallas, L. (2011) investigated the effects of the financial crisis in the context of short-term strategies and policy firms and corporations. The author discusses the reasons for short-termism which to a large extend led to the current economic crisis. He employs classical economic models such as prisoners' dilemma, market for lemons and signaling markets to suggest the ways how to manage short termism in the future.

Sargent-Cox, et al. (2011) investigated the effects of the economic crisis on the mental health of older Australians. The authors claim that older adults are ones of the most vulnerable to poor health outcomes as the result of economic crisis. On the basis of longitudinal study he authors demonstrated statistically significant impact of the economic crisis on worsening mental state, increasing the amount of depression and anxiety symptoms and decreased overall mental status. These effects were not explained by demographical or socioeconomic factors.

Nelson, J. (2012) investigated the differences in the value systems of men and women and discusses whether the values of the women could prevent economic crisis. The author starts with brief review of the literature on the samenessversus-difference debate which he concludes by the notion that the belief in strong behavioral differences between men and women did not find empirical support. On the other hand the author claims that gender is not irrelevant. The second part of the essay discusses the role of gender differences in social construction of financial markets. The author suggests examples and tools that can be used in teaching about the differences and similarities in the context of financial markets.

Felix Roth (Roth, F. 2009) investigated the question of the impact of the economic crisis on the level of public confidence in European countries. Trust in political institutions such as European central bank or the parliament fell significantly in 2008 while confidence in political institutions at the state has not undergone major changes. On this basis, the author puts forward the idea of a possible renationalization of political and financial institutions in Europe as a result of the economic crisis (Roth, F., 2009).

As the reader can see, the literature on the relation of values and economic crisis is manifold and much differentiated (see also Castells et al. 2012, Himanen 2012, Jabbar et al 2014). Leaving the discussion on the value reasons for economic crisis to the other authors, in this paper, we investigate the impact of the economic crisis of 2008 on the value systems in the Czech Republic. We use the representative samples of the first-year students of the Faculty of Humanities, Charles University in Prague to compare the values before during and after crisis (in 2006, 2010 and 2012). Since these students were admitted, but did not yet start their education at the University, the information they would have to learn there did not have a chance to change their values and believes. So, they would rather well represent the overall attitudes of the society comparing to other groups of students. 
We realize that the change in the values of respondents that manifested itself in this paper might occur for the reasons other than economic crisis and there is no statistical way to prove that the differences we see are because of the crisis. However we would like to see, whether our findings would be in the line of the modernization theory of Inglehart and Welzel (2007) which suggest, that lower economic outputs are related to survival values while better economic outcomes are likely to induce the change to self-expression value and the values supporting democratization and civil and political liberties.

\section{Data}

In this paper, we use data collected by the Faculty of Humanities, Charles University in Prague in 2005-2006 (before the economic crisis), in 2010 (after the onset of the economic crisis in Europe) in 2012 (at the end of economic crisis). The overall sample of 1190 respondents consists of the first year students and is representative for the first year. Number of respondents and split upon year and gender are shown in Table 1.

Table 1. Number and gender distribution of the respondents

\begin{tabular}{|lc|c|c|c|c|}
\hline & \multicolumn{3}{|c|}{ Year } & \multirow{2}{*}{ Total } \\
\cline { 3 - 5 } & & 2006 & 2010 & 2012 & \\
\hline \multirow{2}{*}{ Gender } & 547 & 182 & 107 & 368 \\
Total & Memale & 227 & 76 & 54 & 357 \\
\hline
\end{tabular}

The proxies for survival or group values versus self-expression values are listed in table 2.

Table 2. Principles that should govern the society - survival values versus self-expression values

\begin{tabular}{|ll|}
\hline Survival, group values & velf-expression values increasing peoples \\
& priority and entitlements to act
\end{tabular}

Arguably in this list economic result (to earn a lot of money) and technical development represents the only clearly economic survival values. The rest of the value scales we divide according to survival, group values on the left side of the table 2 and self-expression values giving the people priority and entitlement to act according to their choices on the right side of the table 2. For more arguments for this division see Welzel (2002)

\section{Hypotheses}

Following Inglehart and Welzel (2007), Welzel (2002), Inglehart (2004), Inglehart (2008) we expect, that

1) worsening economic conditions in 2010 compared to 2006 lead to a shift of values to survival, group side at the expense of self-expression,

2) partial economic recovery in 2012 supported the change of values back to self-expression values (for the list of values studied see table 2).

\section{Methods}

In order to study the differences in average values of students we employ 95\% confidence intervals supported by two factor ANOVA analysis and Post-Hoc tests. The results are presented in the following chapter.

\section{Findings and Discussion}

In this paper we study the differences in value systems of the first-year students of the Faculty of Humanities, Charles 
University before the crisis of 2008 during the crisis and after the crisis. The results according to each set of values presented in the previous chapter are presented below.

6.1 The principles to be followed by society: economic results (to make a lot of money) versus a quiet life, not to hurry much.

Results on $95 \%$ confidence intervals of the mean values are presented in figure 1. Results comparing average values by ANOVA and Post-Hoc test are presented in Tables 3 and 4.

Figure 1. Mean values and $95 \%$ confidence intervals on a scale of economic output (1) or relaxed unhurried life (5) in 2006, 2010, 2012 years

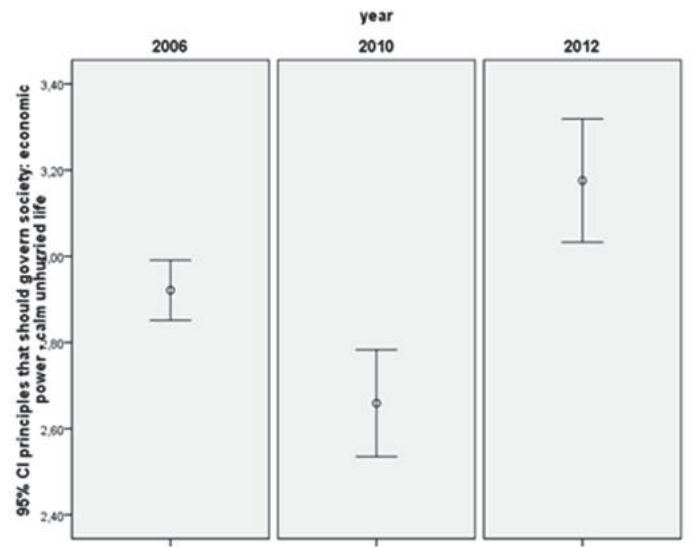

In comparison with 2006, the average value of the variable economic result vs relaxed unhurried life significantly decreased toward economic power in 2010 and increased towards relaxed unhurried life in 2012. This result reflected the overall mood of society, frightened by the economic crisis in 2010 and partially soothed after some economic stability in 2012. By comparing mean values with ANOVA and Post-Hoc test average commitment of respondents to a quiet life at the expense of economic results in 2012 became even higher than in the pre-crisis 2006. This result is consistent with the hypothesis that the society was simply tired of having to pay more attention to the economic side of life and when this aspect of fatigue passes, we can expect a return to the lower values corresponding to more important relaxed unhurried life results.

\subsection{Principles to be followed by society: respect for tradition versus modernization}

Mean values and $95 \%$ confidence intervals are presented in figure 2. Results comparing means by ANOVA and Post-Hoc test are shown in Tables 3 and 4 .

Figure 2. Mean values and 95\% confidence intervals on a scale of respect for traditions (1) - modernization of society (5) in 2006, 2010, 2012

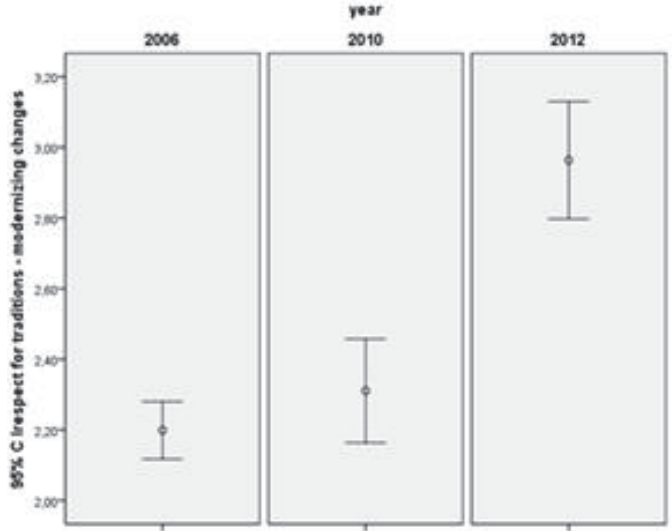


As the figure 2 shows, there is no difference in traditionalist-modernist values in 2006 and 2010. The statistically significant differences presented up in 2012, when on average the respondents supported modernization more at the expense of traditionalism. This result supports the tendency to change something after the crisis, so that the crisis may never happen again.

6.3 Principles to be followed by society: decision making should be based on the opinions of experts versus on the opinions of the public

Mean values and 95\% confidence intervals are presented in figure 3. Results comparing average values by ANOVA and Post-Hoc test are shown in Tables 3 and 4.

Figure 3. Mean values and $95 \%$ confidence intervals on a scale of decision making should be based on the opinions of experts (1) versus on the opinions of the public (5) in 2006, 2010, 2012

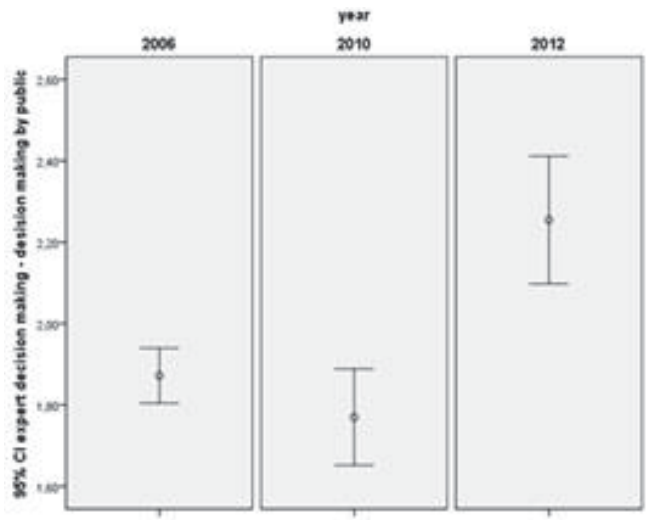

The resulting figure is similar to the previous case, where there is no difference between 2006 and 2010, but an important difference occurs in 2012. In this year the respondents incline more to decision making by public instead by experts. This finding may reflect the disillusion of general public with respect to expert community.

\subsection{Principles to be followed by society: technical development versus spiritual development.}

Mean values and $95 \%$ confidence intervals are presented in figure 4. Results comparing average values by ANOVA and Post-Hoc test are shown in Tables 3 and 4 .

Figure 4. Mean values and $95 \%$ confidence intervals on a scale of technical development (1) versus spiritual development (5) in 2006, 2010, 2012

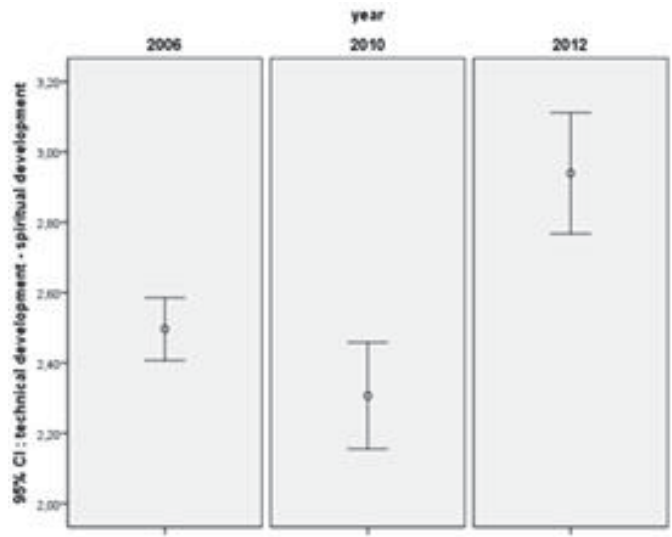


The difference between 2006 and 2010 is not visible on the graph, however it showed up in ANOVA tables (see table 4 in appendix 1). On average in 2010 the respondents were more inclined to technical development at the expense of spiritual development comparing to 2006 and 2012. This result may reflect overall fear of economic crises, while in 2012 the respondents on average supported more spiritual development as the guiding principle for the society. This result is even more pronounced than in 2006.

\subsection{Principles to be followed by society: more rules versus more freedom.}

Mean values and $95 \%$ confidence intervals are presented in figure 5 . Results comparing average values by ANOVA and Post-Hoc test are shown in Tables 3 and 4.

Figure 5. Mean values and 95\% confidence intervals on a scale of more rules (1) versus more freedom (5) in 2006, 2010, 2012

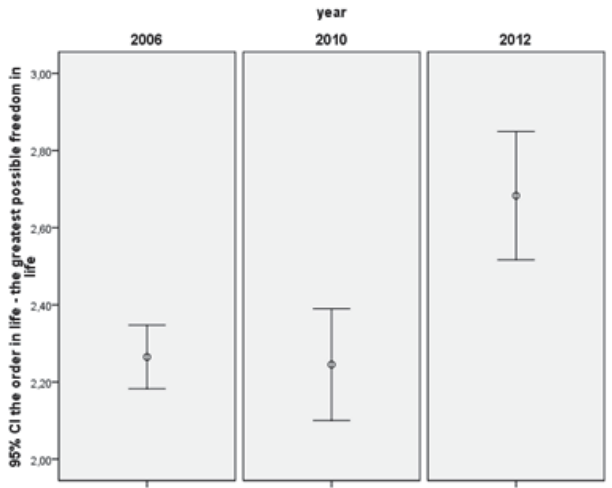

The average attitudes of the respondents as for the trade of between rules and freedom were not statistically significantly different in 2006 and 2010 according to conventional levels. However, the change in average got to be significant in 2012 showing more tendencies to freedom at the expense of rules.

\subsection{Principles to be followed by society: supporting development of outstanding talents vs. sustainable support for all}

Mean values and $95 \%$ confidence intervals are presented in figure 6 . Results comparing average values by ANOVA and Post-Hoc test are presented in Tables 3 and 4 .

Figure 6. Mean values and $95 \%$ confidence intervals on a scale of supporting development of outstanding talents (1) vs. support for all (5) in 2006, 2010, 2012

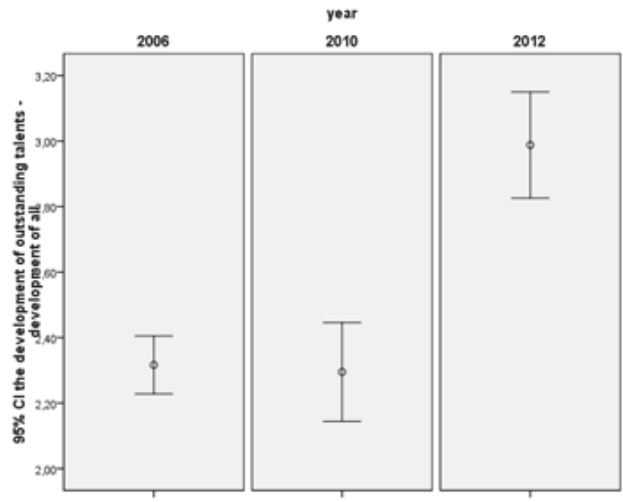

The results are again similar to the previous two cases, where no difference was found in 2006 and 2010, while statistically significant difference showed up in 2012. In 2012 the respondents on average tend more to believe, that society should equally support the development of all the people as opposed to more support to outstanding talents. 


\subsection{Results of One way analysis of variance (ANOVA) and Post-Hoc Tests}

In this section we present the results of one way ANOVA and Post-Hic tests support results presented above (see table 3 and 4).

Table 3. One way analysis of variance (ANOVA) for mean differences in values for years 2006, 2010, and 2012

\begin{tabular}{|c|c|c|c|c|c|c|}
\hline & & $\begin{array}{l}\text { Sum of } \\
\text { Squares }\end{array}$ & df & $\begin{array}{l}\text { Mean } \\
\text { Square }\end{array}$ & $\mathrm{F}$ & Sig. \\
\hline $\begin{array}{l}\text { Compliance with tradition vs modernization and social } \\
\text { change }\end{array}$ & $\begin{array}{l}\text { Between Groups } \\
\text { Within Groups } \\
\text { Total }\end{array}$ & $\begin{array}{c}79,634 \\
1599,003 \\
1678,637\end{array}$ & $\begin{array}{c}2 \\
1197 \\
1199\end{array}$ & $\begin{array}{r}39,817 \\
1,336\end{array}$ & 29,807 &, 000 \\
\hline $\begin{array}{l}\text { Economic result (e.g. to earn a lot of money) vs relaxed } \\
\text { life, not to hurry much }\end{array}$ & $\begin{array}{l}\text { Between Groups } \\
\text { Within Groups } \\
\text { Total }\end{array}$ & $\begin{array}{c}28,052 \\
1164,747 \\
1192,799 \\
\end{array}$ & $\begin{array}{c}2 \\
1197 \\
1199 \\
\end{array}$ & $\begin{array}{c}14,026 \\
, 973\end{array}$ & 14,415 &, 000 \\
\hline $\begin{array}{l}\text { Decision making based upon the opinions of experts vs. } \\
\text { decision making based on the opinions of the public }\end{array}$ & $\begin{array}{l}\text { Between Groups } \\
\text { Within Groups } \\
\text { Total }\end{array}$ & $\begin{array}{c}25,739 \\
1125,853 \\
1151,593 \\
\end{array}$ & $\begin{array}{c}2 \\
1197 \\
1199 \\
\end{array}$ & $\begin{array}{c}12,870 \\
, 941\end{array}$ & 13,683 &, 000 \\
\hline Technical development vs. spiritual development & $\begin{array}{l}\text { Between Groups } \\
\text { Within Groups } \\
\text { Total }\end{array}$ & $\begin{array}{c}41,338 \\
1838,361 \\
1879,699 \\
\end{array}$ & $\begin{array}{c}2 \\
1197 \\
1199 \\
\end{array}$ & $\begin{array}{c}20,669 \\
1,536\end{array}$ & 13,458 &, 000 \\
\hline More rules in society vs. more freedom in society & $\begin{array}{l}\text { Between Groups } \\
\text { Within Groups } \\
\text { Total }\end{array}$ & $\begin{array}{c}25,409 \\
1610,523 \\
1635,932 \\
\end{array}$ & $\begin{array}{c}2 \\
1196 \\
1198 \\
\end{array}$ & $\begin{array}{c}12,704 \\
1,347\end{array}$ & 9,434 &, 000 \\
\hline $\begin{array}{l}\text { Development of outstanding talents vs. development of } \\
\text { all equally, regardless of talent }\end{array}$ & $\begin{array}{l}\text { Between Groups } \\
\text { Within Groups } \\
\text { Total }\end{array}$ & $\begin{array}{c}65,272 \\
1791,708 \\
1856,979\end{array}$ & $\begin{array}{c}2 \\
1197 \\
1199 \\
\end{array}$ & $\begin{array}{c}32,636 \\
1,497\end{array}$ & 21,803 & ,000 \\
\hline
\end{tabular}

In all the cases the null hypothesis on equality of mean values in 2006, 2010 and 2012 can be rejected on 1\% significance levels ( $p$-value presented in table 3 as Sig. are less than 0,01 ). In order to check in which of three years $(2006,2010,2012)$ the mean values were different from the other two we performed Post-Hoc tests presented in table 4. According to able 4 in all the studied cases the mean values in 2012 were significantly different from the other two years (2006 and 2010) on 1\% significance levels. The year 2010 mean values were significantly different from 2006 only in the cases of economic result (e.g. to earn a lot of money) vs relaxed life, not to hurry much, and technical development vs. spiritual development on $5 \%$ significance levels (see table 4).

Table 4. Post-Hoc tests for mean differences in values for years 2006, 2010, and 2012 (LSD method).

\begin{tabular}{|c|c|c|c|c|c|c|c|}
\hline \multirow{2}{*}{ Dependent Variable } & \multirow{2}{*}{\multicolumn{2}{|c|}{$\begin{array}{ll}(\mathrm{l}) & (\mathrm{J}) \\
\text { year } & \text { year }\end{array}$}} & \multirow{2}{*}{$\begin{array}{c}\text { Mean } \\
\text { Difference }(\mathrm{I}-\mathrm{J})\end{array}$} & \multirow{2}{*}{$\begin{array}{l}\text { Std. } \\
\text { Error }\end{array}$} & \multirow{2}{*}{ Sig. } & \multicolumn{2}{|c|}{$\begin{array}{l}95 \% \text { Confidence } \\
\text { Interval }\end{array}$} \\
\hline & & & & & & $\begin{array}{l}\text { Lower } \\
\text { Bound }\end{array}$ & $\begin{array}{l}\text { Upper } \\
\text { Bound }\end{array}$ \\
\hline \multirow{5}{*}{$\begin{array}{l}\text { Economic result (e.g. to earn a lot of money) vs relaxed life, not to } \\
\text { hurry much }\end{array}$} & & 2010 & ,26218* & ,07061 &, 000 & ,1237 & ,4007 \\
\hline & \multirow{2}{*}{2010} & 2006 & $-.26218^{*}$ & 07061 & .000 & -4007 & -1237 \\
\hline & & 2012 &,$- 51675^{*}$ & ,09811 &, 000 &,- 7092 &,- 3243 \\
\hline & \multirow{2}{*}{2012} & 2006 &, $25457^{*}$ & ,08458 &, 003 & 0886 & ,4205 \\
\hline & & 2010 &, $51675^{*}$ & ,09811 &, 000 & ,3243 & ,7092 \\
\hline \multirow{6}{*}{ Compliance with tradition vs modernization and social change } & \multirow{2}{*}{2006} & 2010 &,- 11138 & ,08273 & 178 &,- 2737 & 0509 \\
\hline & & 2012 &,$- 76467^{*}$ & ,09911 &, 000 &,- 9591 &,- 5702 \\
\hline & \multirow{2}{*}{2010} & 2006 &, 11138 & ,08273 & 178 &,- 0509 & ,2737 \\
\hline & & 2012 &,$- 65329^{*}$ & 11495 &, 000 &,- 8788 &,- 4278 \\
\hline & \multirow{2}{*}{2012} & 2006 &, $76467^{\star}$ & 09911 &, 000 &, 5702 & ,9591 \\
\hline & & 2010 & ,65329* & 11495 &, 000 & ,4278 & ,8788 \\
\hline
\end{tabular}




\begin{tabular}{|c|c|c|c|c|c|c|c|}
\hline \multirow{5}{*}{$\begin{array}{l}\text { Decision making based upon the opinions of experts vs. decision } \\
\text { making based on the opinions of the public }\end{array}$} & 2006 & $\begin{array}{l}2010 \\
2012\end{array}$ & $\begin{array}{l}, 10198 \\
-, 38245^{*}\end{array}$ & $\begin{array}{l}, 06942 \\
, 08316\end{array}$ &, 142 & $\begin{array}{l}-, 0342 \\
-, 5456\end{array}$ & $\begin{array}{r}, 2382 \\
-, 2193\end{array}$ \\
\hline & & 2006 &,- 10198 & ,06942 &, 142 &,- 2382 & ,0342 \\
\hline & 2010 & 2012 &,$- 48443^{*}$ & ,09646 &, 000 &,- 6737 &,- 2952 \\
\hline & & 2006 &, $38245^{\star}$ & ,08316 &, 000 & ,2193 &, 5456 \\
\hline & 2012 & 2010 &, $48443^{*}$ & ,09646 &, 000 & ,2952 &, 6737 \\
\hline \multirow{6}{*}{ Technical development vs. spiritual development } & & 2010 &, $18961^{*}$ & ,08870 &, 033 & 0156 & ,3636 \\
\hline & $\angle 006$ & 2012 &,$- 44327^{*}$ &, 10626 &, 000 &,- 6518 &,- 2348 \\
\hline & & 2006 &,$- 18961^{*}$ & ,08870 &, 033 &,- 3636 &,- 0156 \\
\hline & $\angle 010$ & 2012 &,$- 63288^{*}$ & , 12326 &, 000 &,- 8747 &,- 3911 \\
\hline & & 2006 &, $44327^{*}$ & , 10626 &, 000 & ,2348 & ,6518 \\
\hline & $\angle 012$ & 2010 &, $63288^{*}$ &, 12326 &, 000 & ,3911 &, 8747 \\
\hline \multirow{6}{*}{ More rules in society vs. more freedom in society } & & 2010 & 01965 & ,08306 & 813 &,- 1433 & ,1826 \\
\hline & $\angle 000$ & 2012 &,$- 41807^{\star}$ & , 09975 &, 000 &,- 6138 &,- 2224 \\
\hline & & 2006 &,- 01965 & ,08306 & 813 &,- 1826 & ,1433 \\
\hline & 2010 & 2012 &,$- 43772^{*}$ & ,11563 &, 000 &,- 6646 &,- 2109 \\
\hline & & 2006 &, $41807^{*}$ & ,09975 &, 000 & ,2224 & ,6138 \\
\hline & $\angle U 1 L$ & 2010 & ,43772* & 11563 &, 000 & 2109 & ,6646 \\
\hline \multirow{6}{*}{$\begin{array}{l}\text { Development of outstanding talents vs. development of all equally, } \\
\text { regardless of talent }\end{array}$} & & 2010 & ,02152 & ,08757 & 806 &,- 1503 & ,1933 \\
\hline & $\angle 000$ & 2012 &,$- 67134^{*}$ & , 10491 &, 000 &,- 8772 &,- 4655 \\
\hline & & 2006 &,- 02152 & 08757 & 806 &,- 1933 & ,1503 \\
\hline & $\angle 010$ & 2012 &,$- 69286^{*}$ & 12168 &, 000 &,- 9316 &,- 4541 \\
\hline & & 2006 &, $67134^{*}$ & 10491 &, 000 & ,4655 & 8772 \\
\hline & 2012 & 2010 &, $69286^{*}$ & 12168 &, 000 & ,4541 & ,9316 \\
\hline
\end{tabular}

*. The mean difference is significant at the 0.05 level.

\subsection{Summary of results and discussion}

There is little difference between the average four out of six studied values of the respondents in 2006 and 2010. The values where the difference was statistically significant are presented in table 5. Other studied values did not show statistical significance in mean differences.

Table 5. Statistically significant differences in 2010 comparing to 2006

\begin{tabular}{|l|l|}
\hline More important & As opposed to \\
\hline economic outcome & relaxed unhurried life \\
\hline technical development & spiritual development \\
\hline
\end{tabular}

In 2010 economic outcome at the expense of relaxed unhurried life was more important for the respondents comparing to 2006, and technical development at the expense of spiritual development was more important comparing to 2006 (see table 5). This result supports out hypothesis, that worse economic conditions lead to a shift to survival values.

The year of 2012 shows an important rise in all values, which according to the respondents should govern the society. We see more pronounces inclination of the respondents to relaxed unhurried life at the expense of economic output, modernization at the expense of traditions, decision making by public at the expense of decision making by experts, spiritual development as opposed to technical development, and freedom as opposed to more order in life enforced by rules (see table 6).

Table 6. Statistically significant differences in 2012 comparing to 2010 and 2006

\begin{tabular}{|l|l|}
\hline More important in 2012 comparing to 2010 and 2006 & As opposed to \\
\hline relaxed unhurried life & economic output \\
\hline modernization & traditions \\
\hline decision making by public & decision making by experts \\
\hline spiritual development & technical development \\
\hline freedom in life & more order in life enforced by rules \\
\hline equal development of all, regardless of talent & development of outstanding talents \\
\hline
\end{tabular}


This result is in line with our hypothesis that improving economic conditions lead to a shift of all the six studied values toward self-expression side. The interesting result is that worsening of economic condition followed by partial recovery leaded to even greater inclination of the respondents to self-expression values in 2012 comparing to 2006, even though the difference in economic conditions did not support such a shift. Here we would like to propose the hypothesis that not only absolute position of a country on economic development scale is important for the value systems, but the relative change of the economic well-being may play more important role.

\section{Concluding Remarks}

In this paper, we investigated the change of values of students of the Faculty of Humanities, Charles University in Prague before, during and after the last economic crisis. Following Inglehart and Welzel (2007) and Welzel (2002) we tested the hypotheses that

3) worsening economic conditions in 2010 compared to 2006 lead to a shift of values to survival, group side at the expense of self-expression,

4) partial economic recovery in 2012 supported the change of values back to self-expression values (for the list of values studied see table 2).

The first hypothesis proved to be valid for two out of six proxies for survival values, namely the values that directly concerned economic development (economic output versus relaxed unhurried life and technical development versus spiritual development). The second hypothesis was valid for all the cases. Moreover, worsening of economic condition followed by the improvement leaded to a value system even more inclined to self-expression values than before the economic crisis, even though economic condition comparing to the pre-crisis period did not improve much. Here we would like to propose the hypothesis that not only absolute position of a country on economic development scale is important for the value systems, but the relative change of the economic well-being.

\section{References}

Bruton John (2012) The influence of the economic crisis on centre-right values: a Christian Democratic perspective. European View. Centre for European Studies Cornelstown Co. Meath, Dunboyne, Ireland doi: 201210.1007/s12290-012-0223-5

Castells, M., Caraça, J., \& Cardoso, G. (Eds.). (2012). Aftermath: the cultures of the economic crisis. Oxford University Press.

Dallas, L. (2011). Short-termism, the financial crisis, and corporate governance. Journal of Corporation Law, 37, 264.

Himanen, P. (2012). Crisis, Identity, and the Welfare State. Aftermath: The Cultures of the Economic Crisis, 154.

Hofstede, Geert, Gert Jan Hofstede and Michael Minkov. (2010). Cultures and Organizations: Software of the Mind, 3rd ed. New York: McGraw-Hill.

Inglehart R., Welzel Ch. (2007) Modernization, Cultural Change, and Democracy. Cambrige. Cambrige University Press.

Inglehart, R. (Ed.). (2004). Human beliefs and values: A cross-cultural sourcebook based on the 1999-2002 values surveys. Siglo XXI.

Inglehart, R. F. (2008). Changing values among western publics from 1970 to 2006. West European Politics, 31(1-2), 130-146.

Inklaar, Robert \& Yang, Jing. (2012) The impact of financial crises and tolerance for uncertainty, Journal of Development Economics, Elsevier, vol. 97(2), pages 466-480.

Jabbar, S., Yasin, G., Ahmed, U., \& Umair, A. (2014). Transformation of Value System Due to International Integration. A Sociological Analysis Conducted at University of Sargodha. Mediterranean Journal of Social Sciences, 5(16), 552.

Jackson, Kevin T. "Scandal Beneath the Financial Crisis: Getting a View from a Moral-Cultural Mental Model, The." Harv. JL \& Pub. Pol'y 33 (2010): 735.

Nelson, J. (2012). Would Women Leaders Have Prevented the Global Financial Crisis? Implications for Teaching about Gender, Behavior, and Economics. Global development and environment institute. Working paper No. 11-03

Rae, D. (2010). Universities and enterprise education: responding to the challenges of the new era. Journal of Small Business and Enterprise Development, 17(4), 591-606.

Roth, F. (2009). The effect of the financial crisis on systemic trust. Intereconomics, 44(4), 203-208.

Sargent-Cox, K., Butterworth, P., \& Anstey, K. J. (2011). The global financial crisis and psychological health in a sample of Australian older adults: A longitudinal study. Social Science \& Medicine, 73(7), 1105-1112.

Welzel, C. (2002). Effective democracy, mass culture, and the quality of elites: the human development perspective. International Journal of Comparative Sociology, 43(3-5), 317-349.

Welzel, C., Inglehart, R., \& KLIGEMANN, H. D. (2003). The theory of human development: A cross-cultural analysis. European Journal of Political Research, 42(3), 341-379. 